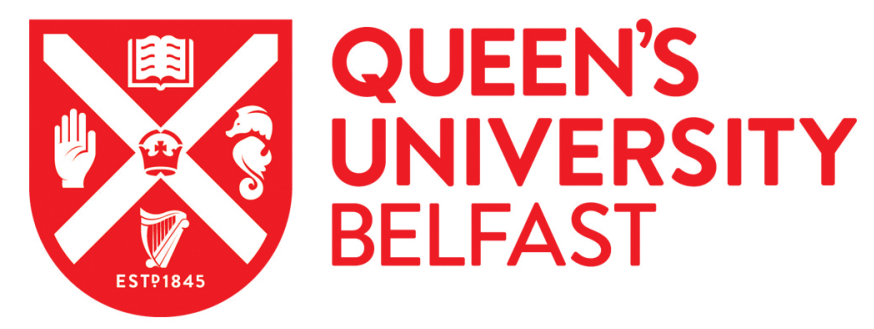

\title{
Periodontitis and Incident Type 2 Diabetes: a prospective cohort study
}

Winning, L., Patterson, C. C., Neville, C. E., Kee, F., \& Linden, G. J. (2016). Periodontitis and Incident Type 2 Diabetes: a prospective cohort study. Journal of Clinical Periodontology. https://doi.org/10.1111/jcpe.12691

\author{
Published in: \\ Journal of Clinical Periodontology
}

Document Version:

Peer reviewed version

Queen's University Belfast - Research Portal:

Link to publication record in Queen's University Belfast Research Portal

\section{Publisher rights}

Copyright ( 2017 John Wiley \& Sons, Inc. All Rights Reserved.

This is the peer reviewed version of the following article, which has been published in final form at

http://onlinelibrary.wiley.com/wol1/doi/10.1111/jcpe.12691/abstract. This article may be used for non-commercial purposes in accordance with Wiley Terms and Conditions for Self-Archiving

\section{General rights}

Copyright for the publications made accessible via the Queen's University Belfast Research Portal is retained by the author(s) and / or other copyright owners and it is a condition of accessing these publications that users recognise and abide by the legal requirements associated with these rights.

Take down policy

The Research Portal is Queen's institutional repository that provides access to Queen's research output. Every effort has been made to ensure that content in the Research Portal does not infringe any person's rights, or applicable UK laws. If you discover content in the Research Portal that you believe breaches copyright or violates any law, please contact openaccess@qub.ac.uk. 
MR. LEWIS WINNING (Orcid ID : 0000-0002-8783-8089)

Received Date : 21-Jun-2016

Revised Date : 15-Dec-2016

Accepted Date : 27-Dec-2016

Article type : Epidemiology (Cohort study or case-control study)

Periodontitis and Incident Type 2 Diabetes: a prospective cohort study.

Running Title: Periodontitis and Incident diabetes

Lewis Winning ${ }^{1}$, Christopher C. Patterson ${ }^{1}$, Charlotte E. Neville ${ }^{1}$, Frank Kee ${ }^{1}$, Gerard J.

Linden ${ }^{1}$

${ }^{1}$ Centre for Public Health, School of Medicine Dentistry and Biomedical Sciences, Queen's

University Belfast, Belfast, Northern Ireland

Keywords: Periodontitis; Incident diabetes; Inflammation.

\section{Correspondence Address:}

Lewis Winning

School of Dentistry

This article has been accepted for publication and undergone full peer review but has not been through the copyediting, typesetting, pagination and proofreading process, which may lead to differences between this version and the Version of Record. Please cite this article as doi: $10.1111 /$ jcpe. 12691

This article is protected by copyright. All rights reserved. 
Queen's University

Grosvenor Road

Belfast

BT12 6BP

Northern Ireland

E-mail: 1.winning@qub.ac.uk

Phone: +44 (0)2890 632733

Fax: +44 (0)2890 438861

\section{Conflict of Interest and Sources of Funding Statement}

The authors declare that there are no conflicts of interest. The study was supported by grants from the British Heart Foundation and the Northern Ireland NHS Research and Development Fund.

\section{Abstract}

Objectives:

To investigate periodontitis as a risk factor for incident type 2 diabetes mellitus (T2DM) in a group of men aged 58-72 years.

This article is protected by copyright. All rights reserved. 
Methods:

1331 dentate, diabetes-free males in Northern Ireland underwent a detailed periodontal examination during 2001-2003. Follow-up was by bi-annual questionnaire and for those reporting diabetes their general medical practitioner was contacted to validate diabetes type, treatment and diagnosis date. Cox's proportional hazard models were used to estimate the effect of periodontitis on incident diabetes. Multivariable analysis included adjustment for various known confounders.

Results:

The mean age of the men was 63.7 (SD 3.0) years. There were 80 cases $(6.0 \%)$ of incident T2DM. Follow-up was for a median period of 7.8 years (IQR 6.7-8.3). After adjusting for confounding variables, the hazard ratio (HR) for incident T2DM in men with moderate / severe periodontitis versus those with no / mild periodontitis was 1.69 (95\% CI 1.06-2.69), $p=0.03$.

\section{Conclusion:}

There was evidence in this homogenous group of dentate men, that those with moderate to severe periodontitis had a significantly increased risk of incident T2DM.

\section{Clinical Relevance}

Scientific rational for the study:

Evidence supporting the role of chronic periodontitis as a putative risk factor for the development of type 2 diabetes mellitus (T2DM) is currently limited.

Principal findings:

This article is protected by copyright. All rights reserved. 
This study showed that in a group of 58-72 year-old Caucasian dentate men in Northern Ireland, baseline moderate to severe periodontitis was an independent risk predictor for the development of T2DM. This relationship was independent of known confounders.

\section{Practical implications:}

Dentists should be aware of the potential systemic health implications of patients presenting with moderate to severe periodontitis. Patients who present with obvious risk factors for T2DM and signs of periodontitis should be informed about their risk for developing T2DM.

\section{Introduction}

Diabetes is an increasing public health concern. In 2015 there were an estimated 415 million people worldwide with diabetes and this is projected to rise to 642 million by 2040 (International Diabetes Federation 2015). The majority (90\%) of these cases are type 2 diabetes mellitus (T2DM). In the United Kingdom (UK), approximately 5\% of the population have diagnosed diabetes, with broadly similar prevalence rates in Northern Ireland (Holman et al. 2015). Diabetes currently accounts for approximately $10 \%$ of the total National Health Service (UK) expenditure and is projected to increase to around 17\% in 2035/2036 (Hex et al 2012).

The bi-directional relationship between diabetes and periodontitis has been recognised for some time (Genco 1996, Kinane \& Chestnutt 1997). Within this relationship, it is well accepted that people with diabetes are more likely to have or develop periodontitis (Chapple et al. 2013), with a threefold higher risk of periodontitis being reported in individuals with diabetes compared to diabetes-free controls (Mealey \& Ocampo 2007). Further to this, there is evidence that the level of metabolic control and duration of diabetes influence future 
periodontal disease risk, with a significant heterogeneity being reported among individuals with diabetes (Demmer et al. 2012, Taylor et al. 2013).

In the reverse direction, there is growing evidence that periodontitis negatively affects glycaemic control in subjects with diabetes (Preshaw et al. 2012). This is further reinforced by interventional studies, where successful periodontal therapy can lead to improvements in glycaemic control in patients suffering from diabetes (Simpson et al. 2015). A recent systematic review has suggested a reduction in glycosylated haemoglobin A1c of $0.5 \%$ after 3 months follow-up (Teshome \& Yitayeh 2016), which is broadly about the order of magnitude expected by adding a second oral antidiabetic medication (Ibrahim et al. 2015).

Acknowledging that periodontitis may potentially have some impact in adversely affecting glycaemic control, it would seem logical to hypothesise periodontitis as a putative risk factor for the development of T2DM. However, evidence supporting this is less well observed at least from prospective population based studies (Taylor et al. 2013). The biological rationale connecting periodontitis with the development of diabetes is inflammation. Periodontitis represents a source of chronic inflammation which contributes to the cumulative systemic inflammatory burden (Paraskevas et al. 2008, Winning et al. 2015). The effects of chronic inflammation are strongly implicated in the development of T2DM (Wang et al. 2013). Despite the biological plausibility of periodontitis being considered a risk factor for T2DM, the complex aetiology of both diseases makes this relationship difficult to determine from clinical studies. This is largely due to confounding by shared risk factors including age, obesity, sex, and some metabolic biomarkers, for both T2DM (Sattar et al. 2008) and periodontitis (Genco \& Borgnakke 2013, Eke et al. 2016, Borgnakke 2016a, Borgnakke 2016b).

This article is protected by copyright. All rights reserved. 
A recent systematic review (Borgnakke et al. 2013) identified just four eligible studies that investigated periodontitis as a risk factor for incident T2DM (Saito et al. 2004, Demmer et al. 2008, Ide et al. 2011, Morita et al. 2012). The populations studied included a nationally representative sample in the United States of America (Demmer et al. 2008), and three Japanese cohorts (Saito et al. 2004, Ide et al. 2011, Morita et al. 2012). Three of the studies reported that severe periodontitis was associated with the development of T2DM, after adjustment for various confounders (Saito et al. 2004, Demmer et al. 2008, Morita et al. 2012). One study found only a tendency for increased risk (Ide et al. 2011). Borgnakke et al. (2013) concluded that there was "scant evidence" for periodontitis promoting the development of T2DM and recommended further studies in different populations. A more recent search of the literature reveals only a small number of further studies investigating periodontitis (Chiu et al. 2015, Miyawaki et al. 2016), or tooth loss (Liljestrand et al. 2015) as risk factors for incident T2DM.

Acknowledging the continued lack of evidence in this area, the aim of the current study therefore, was to determine whether baseline periodontitis associated with the subsequent development of T2DM in a cohort of diabetes-free 58-72 year-old men in Northern Ireland.

\section{Materials and Methods}

The men investigated were participants in the PRIME study (Prospective Epidemiological Study of Myocardial Infarction), which is a longitudinal cohort study of cardiovascular disease in Northern Ireland. From 1991 to 1994, 2748 men were recruited from local industry, the civil service and general medical practices. The sample represented $\sim 5 \%$ of 50 60 year-old men in the greater Belfast region and broadly matched the social class structure of the population (Yarnell 1998).

This article is protected by copyright. All rights reserved. 
From 2001 to 2003, 2010 surviving men attended for re-screening with their date of attendance taken as the baseline. The current study is based on $1400(69.7 \%)$ dentate men who had a comprehensive periodontal examination. Of the remainder, $158(7.8 \%)$ men were edentulous, $363(18.1 \%)$ did not have a dental examination due to the lack of a dental examiner, and $89(4.4 \%)$ refused or had a medical condition that precluded periodontal probing. Exclusion criteria for the present study included men $(n=60)$ with a pre-existing diagnosis of diabetes at baseline. This was assessed by self-report of diabetes at baseline examination, and subsequently verified with the general medical practitioner. In addition, incident T2DM cases that were identified in the first year of follow-up ( $n=9)$ were excluded to minimise the prevalence of undiagnosed baseline diabetes (Demmer et al. 2008). (Figure 1)

Parallel to the periodontal examination, participants completed questionnaires gathering information on their medical history, social circumstances, demographic background and tobacco use. A physical examination assessed anthropometric measures including weight and height. Fasting blood samples were obtained and analysed for total cholesterol level and Creactive protein $(\mathrm{CRP})$.

Approval for the project was obtained from the Research Ethics Committee of the Faculty of Medicine, Queen's University, Belfast and the Office for Research Ethics Committees (Northern Ireland). All participants provided informed, written consent.

Periodontal examination

All periodontal examinations were completed by one of four dental hygienists who had been calibrated against a "gold standard" set by a senior clinical researcher (GL) prior to the study. Regular monthly meetings took place to ensure inter- and intra-examiner consistency and reproducibility. Throughout the study, the hygienists maintained the standard set at the outset 
with $\kappa$ values of $>0.8$ at the regular training sessions (Linden et al. 2009). Clinical periodontal measurements were made using a Michigan O periodontal probe (Hu-Friedy, Chicago, IL, USA) with Williams markings. Clinical measurements were made at the mesial, distal, buccal and palatal/lingual aspects of all teeth excluding third molars. Periodontal probing depths were measured from the gingival margin to the base of the periodontal pocket with the probe tip parallel to the long axis of the tooth. Measurements were made to the nearest millimetre and when any doubt existed the lower value was scored. Clinical attachment level (CAL) was recorded as the distance from the cement-enamel junction (CEJ) to the base of the clinical pocket. This was calculated by measuring the distance from the CEJ to the gingival margin and subtracting this value from the probing depth measurement (recession was recorded as a negative value). None of the men had dental implants. Periodontitis was defined according to the Centers for Disease Control and Prevention and the American Academy of Periodontology (CDC/AAP) classification (Page \& Eke 2007). 'Severe periodontitis' required two or more interproximal sites with $\mathrm{CAL} \geq 6 \mathrm{~mm}$, not on the same tooth, and one or more interproximal sites with PPD $\geq 5 \mathrm{~mm}$. 'Moderate periodontitis' was defined as two or more interproximal sites with CAL $\geq 4 \mathrm{~mm}$, not on the same tooth, or two or more interproximal sites with PPD $\geq 5 \mathrm{~mm}$, not on the same tooth. For either case definition, at least two teeth must be present.

Definitions of variables

Body weight (to the nearest 200g) and height (to the nearest $\mathrm{cm}$ ) were measured by research nurses trained and calibrated according to the PRIME protocol. BMI was thus calculated as weight $/$ height ${ }^{2}\left(\mathrm{~kg} / \mathrm{m}^{2}\right)$. Participants who reported that they had smoked more than 100 cigarettes were questioned about their smoking history. Participants were classified as current, past or never smokers. Pre-existing hypertension was by self-report of the condition in response to the question 'Have you ever been told by a doctor that you have high blood 
pressure (hypertension)?'. Atherosclerotic cardiovascular disease (ACVD) was recorded for men who had a previous diagnosis of coronary heart disease (angina, myocardial infarction), ischemic cerebrovascular disease (stroke/TIA) and peripheral arterial disease. Accurate information pertaining to ACVD was available from the main study database (as this is the primary outcome under investigation in the PRIME study). Socio-economic conditions were categorised based on three proxy indicators: the type of living accommodation (rented or owned/mortgage), number of cars/vans/motorcycles in the household and the number of baths and/or showers and toilets in the home (Wagner et al. 2003). Education was assessed by the number of years in full-time education. Self-reported dental attendance pattern was recorded as 'only when in trouble', 'occasional', or 'regular'. Marital status was categorized into 'married or co-habiting with a partner' versus 'living alone'. Tooth brushing frequency was categorized as 'less than twice per day' or 'two or more times per day' as has previously been applied in similar studies (Reichert et al. 2016). All measurements pertain to the baseline examination, ie. the date they attended for their periodontal examination.

\section{Cohort follow-up}

The study commenced on the day the men attended for their periodontal examination (20012003) and the end of follow-up was $1^{\text {st }}$ April 2010. The men were followed-up bi-annually by questionnaire, and if necessary, by telephone. For those reporting a diabetes diagnosis, or listing a medication that suggested diabetes management, their general medical practitioner (GMP) was contacted to validate the diagnosis, type of diabetes, and its management. GMP diagnosis of diabetes involved a fasting plasma glucose $\geq 7.0 \mathrm{mmol} / 1(126 \mathrm{mg} / \mathrm{dl})$ based on WHO guidelines at that time. If an exact date of diagnosis was not provided, then the midpoint of the year of diagnosis was used. A 'time to diagnosis' was generated based on the date the participant was initially examined and their date of diabetes diagnosis. For those who did not complete the study to the defined end date, 'date of last contact' was taken as the last 
date a man had returned a follow-up questionnaire and data was accordingly censored at this point. Participants who died were censored for type 2 diabetes at the 'date of last contact'.

Statistical analysis

For analysis, the exposure variable, periodontitis, was dichotomised as either no/mild periodontitis or moderate/severe periodontitis. Comparisons of baseline characteristics were made using either the independent samples t-test for continuous variables or the chi-square test for categorical variables. The data for CRP values were not normally distributed, so median CRP values were compared using the Mann-Whitney U test. Tooth brushing frequency was dichotomised as 'less than twice per day' or 'two or more times per day' as has previously been applied (Reichert et al. 2016). For multivariable analysis, CRP values were log transformed and treated as a continuous variable. Comparisons of baseline characteristics were also made based on incident T2DM. A Kaplan-Meier plot was used to display the cumulative incidence of T2DM by periodontal disease status (no / mild periodontitis compared with moderate / severe periodontitis) and a log rank test was used to compare the cumulative T2DM incidence in the two groups. Cox's proportional hazards model was used to estimate the hazard ratio (HR) for incident diabetes in moderate / severe periodontitis cases relative to no / mild periodontitis cases. A series of models was fitted to sequentially adjust for the following potential confounding variables: age, number of teeth, smoking, tooth brushing frequency (model 1), BMI, cholesterol, history of ACVD, hypertension, (model 2), education, dental attendance, marital status, socioeconomic status (model 3), and finally CRP (model 4). In a further analysis, a dose-response relationship was tested by repeating the same Cox's proportional hazard model but splitting the exposure variable periodontitis into three levels: No / mild periodontitis; Moderate periodontitis; and Severe periodontitis. Estimate hazard ratios for incident diabetes in both severe and moderate periodontitis cases relative to no / mild periodontitis cases were calculated and a test for trend 
in cumulative DM incidence was performed across the three categories. Tests of the hazard proportionality assumption were performed using Schoenfeld residuals.

The level of statistical significance was set at $p<0.05$. Analyses were performed using SPSS version 21 (IBM Corp., Armonk, New York) and Stata release 12 (Stata Corp., College Station, Texas).

\section{Results}

A total of 1331 men were included in the study with a median follow-up of 7.8 years (IQR 6.7-8.3). Of the 1331 men, 80men (6.0\%) were diagnosed with T2DM. There were 113 deaths (with 2 men being diagnosed with T2DM prior to death). Of the remainder (1140 men), 1036 completed the study to the date of the last questionnaire. This meant 104 were lost during follow up, equating to a drop-out rate of $7.8 \%$.

The mean age of the 1331 men was 63.7 (SD 3.0), range 58-72 years. Applying the Page \& Eke (2007) criteria, 778 men $(58.5 \%)$ were free from or had mild periodontitis; 282 men (21.2\%) had moderate periodontitis and the remaining 271 men $(20.4 \%)$ had severe periodontitis. At baseline men with moderate/severe periodontitis had fewer teeth $(p=0.01)$, a higher median CRP ( $p=0.02)$, more likely to have smoking exposure $(p<0.001)$, a higher prevalence of hypertension $(p<0.05)$, more likely to be in a lower socio-economic status group $(p<0.01)$, have less years in education $(p<0.01)$, and more likely to attend the dentist 'only when in trouble' $(p<0.01)$ than those with no/mild periodontitis (Table 1). Baseline characteristics were also compared based on incident diabetes (Table 2). The proportion of baseline cases of moderate / severe periodontitis in the incident diabetes group (53\%), was proportionally greater than those in the diabetes-free group, $(41 \%)(p=0.04)$.

This article is protected by copyright. All rights reserved. 
During follow-up, 38 men (4.9\%) with no / mild periodontitis were diagnosed with type 2 diabetes compared with 42 men (7.6\%) categorised with moderate / severe periodontitis. The Kaplan-Meier plot showed that, as time progressed, incident T2DM probability was greater for men with baseline moderate / severe periodontitis (Figure 2). There was a significant difference (log rank test, $p=0.026)$ in the cumulative incidence rates between those with no / mild periodontitis and those that had moderate / severe periodontitis.

The unadjusted hazard ratio (HR) for incident type 2 diabetes in men with moderate / severe periodontitis versus those with mild / no periodontitis was 1.69 (95\% CI 1.07-2.67), $p=0.02$ (Table 3). After sequential adjustment for confounding variables this HR remained stable at 1.69 (95\% CI 1.06-2.69), $p=0.03$. Other co-variates that achieved statistical significance in the fully adjusted model were age with HR 1.11 (95\% CI 1.02-1.20), $p=0.01$ per year increase and BMI with HR 1.21 (95\% CI 1.14-1.29), $p<0.001$ per $\mathrm{kg} / \mathrm{m}^{2}$ increase.

A test for trend across the three categories of periodontal disease (no/mild periodontitis, moderate periodontitis, and severe periodontitis) had a $p=0.018$ in the unadjusted model, whilst in the fully adjusted this attenuated to $p=0.023$. (Table 4)

\section{Discussion}

The main finding of this prospective cohort study, was that baseline moderate to severe periodontitis was an independent risk predictor of incident T2DM in a group of 58-72 year old men. After adjustment for possible confounders, men with baseline moderate to severe periodontitis had a $69 \%$ increased risk of developing T2DM compared to those with no or mild periodontitis. A trend test across the three categories of periodontal disease (no/mild 
periodontitis, moderate periodontitis, and severe periodontitis) was significant, which suggests a dose dependent response relationship in the risk for type 2 diabetes development.

Numerous studies have reported a relationship between periodontitis and diabetes, however, most of this evidence relates to the impact T2DM has on periodontitis (Chapple et al. 2013). Evidence for the reverse, more specifically, the impact periodontitis could have on the development of T2DM is comparatively limited (Borgnakke et al. 2013). Our main finding, that moderate to severe periodontitis was an independent risk predictor of T2DM, is consistent with the outcomes of a small number of previous epidemiological studies (Saito et al. 2004, Demmer et al. 2008, Morita et al. 2012). It is difficult to make direct comparisons between these studies because of major differences in their definition of the exposure variable, periodontitis. Saito et al. (2004), in a community-based study of 961 Japanese individuals, demonstrated that deep pockets were closely related to the development of glucose intolerance. Periodontal examination involved examination of two randomly selected quadrants. Mean periodontal probing depths and attachment loss were analysed, and a score of low, medium or high arbitrarily assigned. Demmer et al. (2008) carried out a 17 year follow-up study on 9,296 diabetes-free men and women enrolled in the National Health and Nutrition Examination Survey (NHANES I) in the United States of America. Periodontal disease, assessed using Russell's Periodontal Index (Russell 1967), was found to be an independent predictor of incident diabetes. The Periodontal Index, which relies on the visual assessment of the presence of gingival inflammation, is considered to be flawed both conceptually and methodologically (Page \& Eke 2007). Morita et al. (2012) assessed 6,125 Japanese diabetes-free subjects and found that the risk of elevation of HbA1c was significantly associated with baseline periodontal pockets of $\geq 6 \mathrm{~mm}$. Periodontal disease was assessed using the Community Periodontal Index (CPI) score (Ainamo et al. 1982). The use of the CPI index may present problems as it is known to not fully represent the severity of 
periodontal disease (Baelum \& Papapanou 1996). In the present study, full mouth periodontal examinations including pocket depths and clinical attachment levels were recorded and the CDC/AAP classification of periodontitis was used (Page \& Eke 2007). There is consensus that these criteria should be used when investigating periodontal systemic linkages (Holtfreter et al. 2015), and it will be of interest to compare the results presented in this study with future studies where the exposure definition is consistent (Linden et al. 2013).

Previous studies, such as Liljestrand et al. (2015), found that the number of missing teeth predicted incident diabetes. It was assumed that tooth loss was a surrogate measure of periodontitis exposure. Number of teeth was included as a discrete variable in our analysis, however, in the fully adjusted model it was not significant. A further analysis was performed (not shown) where we considered a non-linear relationship with tooth loss. Employing the classification of tooth loss used by Lilestrand et al. (2015), again failed to show any significant relationship. Previous evidence has identified caries as the main cause for tooth extractions in British adults (Richards et al. 2005) and so tooth loss is unlikely to be useful as a surrogate measure of previous periodontal disease in a UK based study.

A further variable in our multivariable analysis that was not a significant independent predictor of incident T2DM was CRP, which for a x10 unit increase had an adjusted Hazard Ratio of 0.92 (95\% CI 0.42-2.02). This was unexpected given the strong association between BMI and CRP, and also that CRP has previously been shown to be an independent predictor of incident type 2 diabetes (Pradhan et al. 2001). Such studies, however, are normally performed in middle-aged populations and CRP may be a less reliable predictor of disease in older populations (van der Meer et al. 2003). Inflammation as a mediator represents the most realistic hypothesis to explain the association between periodontitis and diabetes. CRP measurement in the present study was a single measurement taken at baseline. Future studies with repeated time measurements, and the inclusion of a range of other inflammatory

This article is protected by copyright. All rights reserved. 
biomarkers would allow a robust mediation analysis to be performed. Related to CRP level and the onset of type 2 diabetes, may be the effects of medication. In the present study 210 men $(16 \%)$ were taking a statin at baseline. A recent meta-analysis of 13 randomized controlled trials involving 91,140 individuals reported that statin use increased the risk of developing diabetes by $9 \%$ (95\% CI 2-17\%) over a 4-year period compared with those randomized to placebo or standard care (Sattar et al. 2010). In the present study use of statins was potentially associated with an increased risk of incident type 2 diabetes, but not significantly so: unadjusted odds ratio of 1.4 (95\% CI 0.8-2.5). Entering statin use as an explanatory variable in the multivariate modelling (analysis not shown), failed to show any impact on the risk of incident diabetes associated with periodontitis.

The strengths of this study include the homogeneity of the sample: white West-European males, of similar age, who at original recruitment were representative of the general population of Northern Ireland at that time (Yarnell 1998). Ethnicity has previously been shown to have a significant impact on the development of both periodontal disease (DelgadoAngulo et al. 2016), and diabetes (Harris et al. 1998). It should be emphasised that this homogeneity within the sample reduces the possibility of confounding. There was a balance in age and BMI by periodontitis status, and also a balance in smoking by T2DM incidence. Therefore, age, bmi, and smoking were unlikely to confound the observed relationship between periodontitis and incident T2DM. There have been few other such studies in the UK or Europe and so the data presented should prove useful for future comparison between different population groups. Other strengths relate to the prospective design and reasonable follow-up period (median 7.8 years, IQR 6.7-8.3). The majority of participants completed the observational period to the end of study, and men that were lost to follow up or died were appropriately censored at 'date of last contact' (date of last questionnaire returned) in the analysis, meaning the results can be viewed with a degree of confidence. The mean age of the 
men was 63.7 (SD 3.0) years at the start of the incidence study and had broadly similar exposure to potential risk factors pre-disposing to the onset of type 2 diabetes in Western European populations. Due to the design of the PRIME study, with its main aim to investigate putative risk factors for the development of cardiovascular disease, we were able to make use of a range of baseline data on potential confounding factors.

There are several limitations with this study. Firstly, the lack of a fasting blood glucose measure at baseline to exclude undiagnosed baseline diabetes cases. A recent study in a similar age group in Ireland found the prevalence of undiagnosed diabetes to be $0.9 \%$ in a group of 5377 men and women aged over 50 (Leahy et al. 2015). To minimise the risk of identifying undiagnosed pre-existing diabetes as incident T2DM in the present study, we set a threshold for diagnosis of 1 year, similar to Demmer et al. (2008). This meant that a diagnosis within the first year of the prospective study was equated with pre-existing diabetes and was not erroneously recorded as incident. Secondly, the diagnosis of T2DM during follow-up was based on men voluntarily attending their general medical practitioner (GMP). Although attendance for screening of diabetes complications is known to be high in this particular age group (Sargeant et al. 2010), the possibility of under diagnosis cannot be excluded. Related to this, the present study only considered an outcome of T2DM, diagnosed as fasting plasma glucose $\geq 7.0 \mathrm{mmol} / 1$ (126mg/dl). No information was available regarding a diagnosis of prediabetes, therefore, it is unclear what effect periodontitis may have had on the development of this condition. A recent study based on a large Taiwanese population examined the bidirectional relationship between hyperglycaemia and periodontal disease (Chiu et al. 2015). The study examined 5374 participants with an age range of 35-44 years and found periodontal disease presented a $33 \%(95 \%$ CI 9-63\%) increase in risk of incident hyperglycaemia (including diabetes) after controlling for potential confounding factors. Arora et al. (2014) examined the relationship between periodontitis, impaired fasting glucose and 
impaired glucose tolerance in 1165 diabetes-free adults enrolled in the National Health and Nutrition Examination Survey (NHANES) 2009-2010. Applying the CDC/AAP classification used in the present study the odds ratios for having impaired glucose tolerance among participants with moderate or severe periodontitis, relative to those with none/mild periodontitis were 1.07 (95\% CI 0.50-2.25) and 1.93 (1.18-3.17). Although this was a cross sectional analysis, the findings are suggestive of a role for periodontitis in the aetiology of impaired glucose regulation. Similar findings have also been corroborated by a number of other studies investigating the relationship between periodontitis and pre-diabetes (Demmer et al. 2015, Choi et al. 2011, Zadik et al. 2010). Thirdly, a major limitation is the lack of any further information on the men's periodontal status. Men were seen for a one-off examination on entry to the study with no intervention being performed. Those with periodontitis were informed and advised to attend with a dentist. We do not know whether these participants went on to have any periodontal intervention performed. Similarly, it is unknown whether men initially classified as no / mild periodontitis may have developed disease during the observation time. Both scenarios may impact the level of inflammation, which as previously discussed is suspected to be the underlying mechanism of the relationship with T2DM. Fourthly, 113 men $(8.5 \%)$ died during follow-up and whilst T2DM was diagnosed in two of these men prior to death it does introduce the possibility of survival bias, and it is not known what impact this may have on the proportional hazards modelling. However, if the relationship between periodontitis and diabetes is causal, its effect might be expected to be stronger than that reported. Fifthly, this study was limited to men in a 58-72 year old age group, and we cannot therefore extrapolate findings to women or other age groups. Fifthly, the clinical periodontal measurements of subjects in this study were made at the mesial, distal, buccal and palatal/lingual aspects of all teeth. This represents a modification of the sites suggested by the CDC/AAP case definition (Page \& Eke 2007), which are based on the 
four proximal sites, namely the mesiobuccal, distobuccal, distolingual, and mesiolingual sites. It is acknowledged that this may have led to an underestimation of periodontal disease prevalence in this cohort. Finally, in common with all observational studies, the possibility of residual confounding or failure to account for other potential confounders exists.

\section{Conclusion}

In conclusion, baseline moderate to severe periodontitis was an independent risk predictor of incident T2DM in a group of 58-72 year old men in Northern Ireland. This relationship was independent of known confounders for incident T2DM, and could reflect a shared biological pathway between periodontitis and diabetes. Alternatively, periodontal disease may be an etiologic factor for T2DM. Further studies should be aimed at specifically addressing the issue of causality, and the mechanistic process regarding the potential impact of periodontitis on the disease process of diabetes.

\section{Acknowledgements}

The authors acknowledge the help of the research nurses and dental hygienists who examined the men from the PRIME study.

\section{References}

Ainamo, J., Barmes, D., Beagrie, G., Cutress, T., Martin, J. \& Sardo-Infirri, J. (1982)

Development of the World Health Organization (WHO) community periodontal index of treatment needs (CPITN). International Dental Journal 32, 281-291.

This article is protected by copyright. All rights reserved. 
Arora, N., Papapanou, P. N., Rosenbaum, M., Jacobs, D. R.,Jr, Desvarieux, M. \& Demmer, R. T. (2014) Periodontal infection, impaired fasting glucose and impaired glucose tolerance: results from the Continuous National Health and Nutrition Examination Survey 2009-2010. Journal of Clinical Periodontology 41, 643-652.

Baelum, V. \& Papapanou, P. N. (1996) CPITN and the epidemiology of periodontal disease. Community Dentistry and Oral Epidemiology 24, 367-368.

Borgnakke, W. S. (2016a) Modifiable Risk Factors for Periodontitis and Diabetes. Current Oral Health Reports 3, 254-269. doi:10.1007/s40496-016-0099-6.

Borgnakke, W. S. (2016b) “Non-modifiable” Risk Factors for Periodontitis and Diabetes. Current Oral Health Reports 3, 270-281. doi:10.1007/s40496-016-0098-7.

Borgnakke, W. S., Ylostalo, P. V., Taylor, G. W. \& Genco, R. J. (2013) Effect of periodontal disease on diabetes: systematic review of epidemiologic observational evidence. Journal of Clinical Periodontology 40 Suppl 14, S135-52.

Chapple, I. L., Genco, R. \& Working group 2 of joint EFP/AAP workshop. (2013) Diabetes and periodontal diseases: consensus report of the Joint EFP/AAP Workshop on Periodontitis and Systemic Diseases. Journal of Clinical Periodontology 40 Suppl 14, S106-12.

Chiu, S. Y., Lai, H., Yen, A. M., Fann, J. C., Chen, L. S. \& Chen, H. H. (2015) Temporal sequence of the bidirectional relationship between hyperglycemia and periodontal disease: a community-based study of 5,885 Taiwanese aged 35-44 years (KCIS No. 32). Acta Diabetologica 52, 123-131.

This article is protected by copyright. All rights reserved. 
Choi, Y. H., McKeown, R. E., Mayer-Davis, E. J., Liese, A. D., Song, K. B. \& Merchant, A. T. (2011) Association between periodontitis and impaired fasting glucose and diabetes. Diabetes Care 34, 381-386.

Delgado-Angulo, E. K., Bernabe, E. \& Marcenes, W. (2016) Ethnic inequalities in periodontal disease among British adults. Journal of Clinical Periodontology 43, 926933.

Demmer, R. T., Holtfreter, B., Desvarieux, M., Jacobs, D. R.,Jr, Kerner, W., Nauck, M., Volzke, H. \& Kocher, T. (2012) The influence of type 1 and type 2 diabetes on periodontal disease progression: prospective results from the Study of Health in Pomerania (SHIP). Diabetes Care 35, 2036-2042.

Demmer, R. T., Jacobs, D. R.,Jr \& Desvarieux, M. (2008) Periodontal disease and incident type 2 diabetes: results from the First National Health and Nutrition Examination Survey and its epidemiologic follow-up study. Diabetes Care 31, 1373-1379.

Demmer, R. T., Jacobs, D. R.,Jr, Singh, R., Zuk, A., Rosenbaum, M., Papapanou, P. N. \& Desvarieux, M. (2015) Periodontal Bacteria and Prediabetes Prevalence in ORIGINS: The Oral Infections, Glucose Intolerance, and Insulin Resistance Study. Journal of Dental Research 94, 201S-11S.

Eke, P. I., Wei, L., Thornton-Evans, G. O., Borrell, L. N., Borgnakke, W. S., Dye, B. \& Genco, R. J. (2016) Risk Indicators for Periodontitis in US Adults: NHANES 2009 to 2012. Journal of Periodontology 87, 1174-1185.

Genco, R. J. (1996) Current view of risk factors for periodontal diseases. Journal of Periodontology 67, 1041-1049. 
Genco, R. J. \& Borgnakke, W. S. (2013) Risk factors for periodontal disease. Periodontology $200062,59-94$.

Harris, M., Flegal, K., Cowie, C., Eberhardt, M., Goldstein, D., Little, R., Wiedmeyer, H. \& Byrd-Holt, D. (1998) Prevalence of diabetes, impaired fasting glucose, and impaired glucose tolerance in US adults - The Third National Health and Nutrition Examination Survey, 1988-1994. Diabetes Care 21, 518-524.

Hex, N., Bartlett, C., Wright, D., Taylor, M. \& Varley, D. (2012) Estimating the current and future costs of Type 1 and Type 2 diabetes in the UK, including direct health costs and indirect societal and productivity costs. Diabetic Medicine: A Journal of the British Diabetic Association 29, 855-862.

Holman, N., Young, B. \& Gadsby, R. (2015) Current prevalence of Type 1 and Type 2 diabetes in adults and children in the UK. Diabetic Medicine: A Journal of the British Diabetic Association 32, 1119-1120.

Holtfreter, B., Albandar, J. M., Dietrich, T., Dye, B. A., Eaton, K. A., Eke, P. I., Papapanou, P. N., Kocher, T. \& Joint EU/USA Periodontal Epidemiology Working Group. (2015) Standards for reporting chronic periodontitis prevalence and severity in epidemiologic studies: Proposed standards from the Joint EU/USA Periodontal Epidemiology Working Group. Journal of Clinical Periodontology 42, 407-412.

Ibrahim, M., Abu Al Magd, M., Annabi, F. A., Assaad-Khalil, S., Ba-Essa, E. M., Fahdil, I., Karadeniz, S., Meriden, T., Misha'1, A. A., Pozzilli, P., Shera, S., Thomas, A., Bahijri, S., Tuomilehto, J., Yilmaz, T. \& Umpierrez, G. E. (2015) Recommendations for management of diabetes during Ramadan: update 2015. BMJ Open Diabetes Research \& Care 3, e000108.

This article is protected by copyright. All rights reserved. 
Ide, R., Hoshuyama, T., Wilson, D., Takahashi, K. \& Higashi, T. (2011) Periodontal disease and incident diabetes: a seven-year study. Journal of Dental Research 90, 41-46.

International Diabetes Federation. (2015) IDF diabetes atlas, 7 ed., Brussels, Belgium. International Diabetes Federation.

Kinane, D. F. \& Chestnutt, I. G. (1997) Relationship of diabetes to periodontitis. Current Opinion in Periodontology 4, 29-34.

Leahy, S., O'Halloran, A. M., O'Leary, N., Healy, M., McCormack, M., Kenny, R. A. \& O'Connell, J. (2015) Prevalence and correlates of diagnosed and undiagnosed type 2 diabetes mellitus and pre-diabetes in older adults: Findings from the Irish Longitudinal Study on Ageing (TILDA). Diabetes Research and Clinical Practice 110, 241-249.

Liljestrand, J. M., Havulinna, A. S., Paju, S., Mannisto, S., Salomaa, V. \& Pussinen, P. J. (2015) Missing teeth predict incident cardiovascular events, diabetes, and death. Journal of Dental Research 94, 1055-1062.

Linden, G. J., Lyons, A. \& Scannapieco, F. A. (2013) Periodontal systemic associations: review of the evidence. Journal of Clinical Periodontology 40 Suppl 14, S8-19.

Linden, G. J., McClean, K. M., Woodside, J. V., Patterson, C. C., Evans, A., Young, I. S. \& Kee, F. (2009) Antioxidants and periodontitis in 60-70-year-old men. Journal of Clinical Periodontology 36, 843-849.

Mealey, B. L. \& Ocampo, G. L. (2007) Diabetes mellitus and periodontal disease. Periodontology 2000 44, 127-153. 
Miyawaki, A., Toyokawa, S., Inoue, K., Miyoshi, Y. \& Kobayashi, Y. (2016) Self-Reported Periodontitis and Incident Type 2 Diabetes among Male Workers from a 5-Year FollowUp to MY Health Up Study. Plos One 11, e0153464.

Morita, I., Inagaki, K., Nakamura, F., Noguchi, T., Matsubara, T., Yoshii, S., Nakagaki, H., Mizuno, K., Sheiham, A. \& Sabbah, W. (2012) Relationship between periodontal status and levels of glycated hemoglobin. Journal of Dental Research 91, 161-166.

Page, R. C. \& Eke, P. I. (2007) Case definitions for use in population-based surveillance of periodontitis. Journal of Periodontology 78, 1387-1399.

Paraskevas, S., Huizinga, J. D. \& Loos, B. G. (2008) A systematic review and meta-analyses on C-reactive protein in relation to periodontitis. Journal of Clinical Periodontology 35, 277-290.

Preshaw, P. M., Alba, A. L., Herrera, D., Jepsen, S., Konstantinidis, A., Makrilakis, K. \& Taylor, R. (2012) Periodontitis and diabetes: a two-way relationship. Diabetologia 55, 21-31.

Reichert, S., Schulz, S., Benten, A. C., Lutze, A., Seifert, T., Schlitt, M., Werdan, K., Hofmann, B., Wienke, A., Schaller, H. G. \& Schlitt, A. (2016) Periodontal conditions and incidence of new cardiovascular events among patients with coronary vascular disease. Journal of Clinical Periodontology 43, 918-925.

Richards, W., Ameen, J., Coll, A. M. \& Higgs, G. (2005) Reasons for tooth extraction in four general dental practices in South Wales. British Dental Journal 198, 275-278.

Russell, A. L. (1967) The Periodontal Index. Journal of Periodontology 38, Suppl:585-91. 
Saito, T., Shimazaki, Y., Kiyohara, Y., Kato, I., Kubo, M., Iida, M. \& Koga, T. (2004) The severity of periodontal disease is associated with the development of glucose intolerance in non-diabetics: the Hisayama study. Journal of Dental Research 83, 485-490.

Sargeant, L. A., Simmons, R. K., Barling, R. S., Butler, R., Williams, K. M., Prevost, A. T., Kinmonth, A. L., Wareham, N. J. \& Griffin, S. J. (2010) Who attends a UK diabetes screening programme? Findings from the ADDITION-Cambridge study. Diabetic Medicine 27, 995-1003.

Sattar, N., Wannamethee, S. G. \& Forouhi, N. G. (2008) Novel biochemical risk factors for type 2 diabetes: pathogenic insights or prediction possibilities? Diabetologia 51, 926940.

Simpson, T. C., Weldon, J. C., Worthington, H. V., Needleman, I., Wild, S. H., Moles, D. R., Stevenson, B., Furness, S. \& Iheozor-Ejiofor, Z. (2015) Treatment of periodontal disease for glycaemic control in people with diabetes mellitus. The Cochrane Database of Systematic Reviews (11):CD004714. doi, CD004714.

Taylor, J. J., Preshaw, P. M. \& Lalla, E. (2013) A review of the evidence for pathogenic mechanisms that may link periodontitis and diabetes. Journal of Clinical Periodontology 40 Suppl 14, S113-34.

Teshome, A. \& Yitayeh, A. (2016) The effect of periodontal therapy on glycemic control and fasting plasma glucose level in type 2 diabetic patients: systematic review and metaanalysis. BMC Oral Health 17, 31-016-0249-1.

Wagner, A., Simon, C., Evans, A., Ducimetiere, P., Bongard, V., Montaye, M., Arveiler, D. \& PRIME Study Group. (2003) Physical activity patterns in 50-59 year men in France 
and Northern Ireland. Associations with socio-economic status and health behaviour. European Journal of Epidemiology 18, 321-329.

Wang, X., Bao, W., Liu, J., Ouyang, Y. Y., Wang, D., Rong, S., Xiao, X., Shan, Z. L., Zhang, Y., Yao, P. \& Liu, L. G. (2013) Inflammatory markers and risk of type 2 diabetes: a systematic review and meta-analysis. Diabetes Care 36, 166-175.

Winning, L., Patterson, C. C., Cullen, K. M., Stevenson, K. A., Lundy, F. T., Kee, F. \& Linden, G. J. (2015) The association between subgingival periodontal pathogens and systemic inflammation. Journal of Clinical Periodontology 42, 799-806.

Yarnell, J. W. (1998) The PRIME study: classical risk factors do not explain the severalfold differences in risk of coronary heart disease between France and Northern Ireland. Prospective Epidemiological Study of Myocardial Infarction. Quarterly Journal of Medicine 91, 667-676.

Zadik, Y., Bechor, R., Galor, S. \& Levin, L. (2010) Periodontal disease might be associated even with impaired fasting glucose. British Dental Journal 208, E20.

\section{Table and Figure Legends}

Table 1. Baseline characteristics by periodontitis severity $(\mathrm{n}=1,331)$.

Table 2. Baseline characteristics by final incident diabetes status $(\mathrm{n}=1,331)$.

This article is protected by copyright. All rights reserved. 
Table 3. Risk for incident type 2 diabetes by adjustment of various confounders $(n=1331)$.

Table 4. Dose-response risk for incident type 2 diabetes by adjustment of various confounders $(n=1331)$.

Figure 1. Recruitment and enrolment of study participants.

Figure 2. Cumulative incident type 2 diabetes by periodontitis severity status during study duration $(\mathrm{n}=1,331){ }^{*}$

Footnote: *Kaplan Meier survival analysis.

This article is protected by copyright. All rights reserved. 
Table 1. Baseline characteristics by periodontitis severity $(n=1,331)$.

\begin{tabular}{|c|c|c|c|}
\hline & $\begin{array}{c}\text { No / mild } \\
\text { periodontitis }\end{array}$ & $\begin{array}{l}\text { Moderate / severe } \\
\text { periodontitis }\end{array}$ & \multirow[t]{2}{*}{$p$} \\
\hline & $\mathrm{n}=778$ & $\mathrm{n}=553$ & \\
\hline \multicolumn{4}{|l|}{ Age, years } \\
\hline mean $(\mathrm{SD})$ & $63.6(2.9)$ & $63.8(3.0)$ & 0.34 \\
\hline range & $58-71$ & $58-72$ & \\
\hline \multicolumn{4}{|l|}{ Number of teeth } \\
\hline mean (SD) & $19.9(5.9)$ & $19.0(6.2)$ & 0.01 \\
\hline range & $1-28$ & $2-28$ & \\
\hline \multicolumn{4}{|l|}{ Total cholesterol, mmol/L } \\
\hline \multicolumn{4}{|l|}{$\mathrm{BMI}, \mathrm{kg} / \mathrm{m}^{2}$} \\
\hline mean(SD) & $27.4(3.5)$ & $27.4(3.6)$ & 0.82 \\
\hline $\begin{array}{l}\mathrm{CRP}, \mathrm{mg} / \mathrm{L} \\
\text { median (IQR) }\end{array}$ & $1.4(1.0$ to 2.3$)$ & $1.6(1.0$ to 2.7$)$ & 0.02 \\
\hline \multicolumn{4}{|l|}{ Smoking } \\
\hline Never & $348(44.7 \%)$ & $187(33.8 \%)$ & \\
\hline Past & $335(43.1 \%)$ & $223(42.1 \%)$ & $<0.001$ \\
\hline Current & $95(12.2 \%)$ & $133(24.1 \%)$ & \\
\hline \multicolumn{4}{|l|}{ Hypertension } \\
\hline $\mathrm{n}(\%)$ & $213(27.4 \%)$ & $179(32.4 \%)$ & 0.047 \\
\hline \multicolumn{4}{|l|}{ ACVD } \\
\hline $\mathrm{n}(\%)$ & $67(8.6 \%)$ & $54(9.8 \%)$ & 0.47 \\
\hline \multicolumn{4}{|l|}{$\begin{array}{l}\text { Socio-economic conditions } \\
\mathrm{n}(\%)\end{array}$} \\
\hline Low & $225(28.9 \%)$ & $206(37.3 \%)$ & \\
\hline Medium & $188(24.2 \%)$ & $122(22.1 \%)$ & 0.006 \\
\hline High & $365(46.9 \%)$ & $225(40.7 \%)$ & \\
\hline \multicolumn{4}{|l|}{ Education, years } \\
\hline mean $(\mathrm{SD})$ & $11.8(3.0)$ & $11.4(2.8)$ & 0.03 \\
\hline range & $6-24$ & $5-26$ & \\
\hline \multicolumn{4}{|l|}{ Lives alone } \\
\hline $\mathrm{n}(\%)$ & $81(10.4 \%)$ & $73(13.2 \%)$ & 0.12 \\
\hline \multicolumn{4}{|l|}{$\begin{array}{l}\text { Dental attendance } \\
\mathrm{n}(\%)\end{array}$} \\
\hline "Regular" & $554(71.2 \%)$ & $358(64.9 \%)$ & \\
\hline "Occasional" & $75(9.6 \%)$ & $47(8.5 \%)$ & 0.005 \\
\hline "Only when in trouble" & $149(19.2 \%)$ & $147(26.6 \%)$ & \\
\hline $\begin{array}{l}\text { Tooth brushing <x } 2 / \text { day } \\
\mathrm{n}(\%)\end{array}$ & $30(3.9 \%)$ & $25(4.6 \%)$ & 0.53 \\
\hline
\end{tabular}

$\mathrm{BMI}=$ body mass index; $\mathrm{ACVD}=$ atherosclerotic cardiovascular disease; $\mathrm{CRP}=\mathrm{C}$-reactive protein; $\mathrm{n}=$ number of men; $\mathrm{SD}=$ standard deviation; $\mathrm{IQR}=$ inter quartile range; values in bold signify statistical significance $\mathrm{p}<0.05$.

This article is protected by copyright. All rights reserved. 
Table 2. Baseline characteristics by final incident diabetes status $(n=1,331)$.

\begin{tabular}{|c|c|c|c|}
\hline & \multicolumn{2}{|c|}{ Developed diabetes } & \multirow[t]{2}{*}{$p$} \\
\hline & Yes $(n=80)$ & No $(n=1251)$ & \\
\hline \multicolumn{4}{|l|}{ Age, years } \\
\hline mean $(\mathrm{SD})$ & $64.1(2.9)$ & $63.7(3.0)$ & 0.21 \\
\hline range & $59-71$ & $58-72$ & \\
\hline \multicolumn{4}{|l|}{ Number of teeth } \\
\hline mean $(\mathrm{SD})$ & $19.3(6.0)$ & $19.6(6.0)$ & 0.68 \\
\hline range & $1-28$ & $1-28$ & \\
\hline \multicolumn{4}{|c|}{ Mod/Severe Periodontitis cases } \\
\hline $\mathrm{n}(\%)$ & $42(52.5 \%)$ & $511(40.8 \%)$ & 0.04 \\
\hline $\begin{array}{l}\text { Total cholesterol, } \mathrm{mmol} / \mathrm{L} \\
\text { mean }(\mathrm{SD})\end{array}$ & $5.3(0.9)$ & $5.4(1.0)$ & 0.34 \\
\hline $\begin{array}{l}\text { BMI, } \mathrm{kg} / \mathrm{m}^{2} \\
\text { mean }(\mathrm{SD})\end{array}$ & \multicolumn{3}{|c|}{ BMI, $\mathrm{kg} / \mathrm{m}^{2}$} \\
\hline \multicolumn{4}{|l|}{$\mathrm{CRP}, \mathrm{mg} / \mathrm{L}$} \\
\hline \multicolumn{4}{|l|}{ Smoking } \\
\hline Never & $35(43.8 \%)$ & $500(40.0 \%)$ & \\
\hline Past & $32(40.0 \%)$ & $536(42.8 \%)$ & 0.80 \\
\hline Current & $13(16.3 \%)$ & $215(17.2 \%)$ & \\
\hline \multicolumn{4}{|l|}{ Hypertension } \\
\hline $\mathrm{n}(\%)$ & $30(37.5 \%)$ & $362(29.0 \%)$ & 0.10 \\
\hline \multicolumn{4}{|l|}{ ACVD } \\
\hline $\mathrm{n}(\%)$ & $10(12.5 \%)$ & $111(8.9 \%)$ & 0.27 \\
\hline \multicolumn{4}{|l|}{$\begin{array}{l}\text { Socio-economic conditions } \\
\mathrm{n}(\%)\end{array}$} \\
\hline Low & $29(36.3 \%)$ & $402(32.1 \%)$ & \\
\hline Medium & $22(27.5 \%)$ & $288(23.0 \%)$ & 0.32 \\
\hline High & $29(36.3 \%)$ & $561(44.8 \%)$ & \\
\hline \multicolumn{4}{|l|}{ Education, years } \\
\hline mean $(\mathrm{SD})$ & $11.3(2.7)$ & $11.7(2.9)$ & 0.26 \\
\hline range & $8-21$ & $5-26$ & \\
\hline \multicolumn{4}{|l|}{ Lives alone } \\
\hline $\mathrm{n}(\%)$ & $14(17.5 \%)$ & $140(11.2 \%)$ & 0.09 \\
\hline \multicolumn{4}{|l|}{$\begin{array}{l}\text { Dental attendance } \\
\mathrm{n}(\%)\end{array}$} \\
\hline "Regular" & $56(70.0 \%)$ & $856(68.5 \%)$ & \\
\hline "Occasional" & $4(5 \%)$ & $118(9.4 \%)$ & 0.38 \\
\hline "Only when in trouble" & $20(25 \%)$ & $276(22.1 \%)$ & \\
\hline $\begin{array}{l}\text { Tooth brushing }<x 2 / \text { day } \\
\mathrm{n}(\%)\end{array}$ & $4(5.1 \%)$ & $51(4.1 \%)$ & 0.67 \\
\hline
\end{tabular}

This article is protected by copyright. All rights reserved. 
Table 3. Risk for incident type 2 diabetes by adjustment of various confounders $(n=1331)$.

\begin{tabular}{|c|c|c|c|c|c|}
\hline & Crude model* ${ }^{*}$ & Model 1* & Model 2* & Model 3* & Model 4* \\
\hline & $\mathrm{HR}(95 \% \mathrm{CI})$ & $\mathrm{HR}(95 \% \mathrm{CI})$ & $\mathrm{HR}(95 \% \mathrm{CI})$ & $\mathrm{HR}(95 \% \mathrm{CI})$ & $\mathrm{HR}(95 \% \mathrm{CI})$ \\
\hline Periodontal status (moderate/severe versus no/mild) & $1.69(1.07-2.67)$ & $1.69(1.06-2.68)$ & $1.70(1.07-2.71)$ & $1.68(1.06-2.68)$ & $1.69(1.06-2.69)$ \\
\hline Age (1 year increase) & & $1.08(1.00-1.17)$ & $1.10(1.02-1.20)$ & $1.11(1.02-1.20)$ & $1.11(1.02-1.20)$ \\
\hline Number of teeth (per tooth increase) & & $0.99(0.95-1.03)$ & $1.00(0.96-1.04)$ & $1.00(0.96-1.05)$ & $1.00(0.96-1.05)$ \\
\hline \multicolumn{6}{|l|}{ Smoking } \\
\hline Previous versus Never & & $0.90(0.54-1.49)$ & $0.78(0.47-1.29)$ & $0.78(0.47-1.31)$ & $0.79(0.47-1.31)$ \\
\hline Current versus Never & & $0.88(0.44-1.73)$ & $0.95(0.48-1.88)$ & $0.91(0.46-1.80)$ & $0.91(0.46-1.81)$ \\
\hline Tooth brushing frequency ( $<2 /$ day versus $\geq 2 /$ day) & & $1.27(0.46-3.50)$ & $1.01(0.36-2.82)$ & $1.00(0.35-2.88)$ & $1.00(0.35-2.90)$ \\
\hline
\end{tabular}

BMI (per $\mathrm{kg} / \mathrm{m}^{2}$ increase)

Cholesterol (per mmol/L increase)

ACVD (Yes versus No)

Hypertension (Yes versus No)

$1.22(\mathbf{1 . 1 5 - 1 . 2 9 )}$

$0.98(0.76-1.28)$

$1.42(0.68-2.95)$

$1.06(0.65-1.74)$
1.21 (1.14-1.29)

0.99 (0.77-1.28)

$1.42(0.68-2.95)$

$1.04(0.63-1.72)$

$0.99(0.90-1.09)$

$0.64(0.23-1.77)$

$0.99(0.55-1.76)$

$1.31(0.74-2.32)$

$1.54(0.87-2.74)$

$1.47(0.76-2.82)$
1.21 (1.14-1.29)

$0.99(0.77-1.28)$

$1.41(0.68-2.95)$

$1.04(0.63-1.72)$

$0.99(0.90-1.09)$

$0.64(0.23-1.77)$

$0.99(0.55-1.76)$

$1.32(0.74-2.35)$

$1.55(0.87-2.76)$

$1.47(0.76-2.82)$

Model $1+$ adjustment for baseline BMI, cholesterol, history of atherosclerotic cardiovascular disease, history of hypertension. Model $3=$ Model $2+$ adjustment for history of education years, dental attendance, marital status, and socioeconomic status.

$\mathrm{BMI}=$ body mass index; $\mathrm{ACVD}=$ atherosclerotic cardiovascular disease; $\mathrm{CRP}=\mathrm{C}$-reactive protein; $\mathrm{HR}=$ hazard ratio; $\mathrm{CI}=$ confidence interval; values in bold signify statistical significance $\mathrm{p}<0.05$.

This article is protected by copyright. All rights reserved. 
Table 4. Dose-response risk for incident type 2 diabetes by adjustment of various confounders $(\mathrm{n}=1331)$.

\begin{tabular}{|c|c|c|c|c|c|}
\hline & Crude model* & Model 1* & Model 2* & Model 3* & Model 4* \\
\hline & $\mathrm{HR}(95 \% \mathrm{CI})$ & $\mathrm{HR}(95 \% \mathrm{CI})$ & $\mathrm{HR}(95 \% \mathrm{CI})$ & $\mathrm{HR}(95 \% \mathrm{CI})$ & HR $(95 \% \mathrm{CI})$ \\
\hline \multicolumn{6}{|l|}{ Periodontal status } \\
\hline Moderate V No / mild & $1.53(0.86-2.69)$ & $1.55(0.87-2.75)$ & $1.58(0.89-2.81)$ & $1.53(0.86-2.73)$ & $1.53(0.86-2.74)$ \\
\hline Severe V No / mild & $1.87(1.09-3.22)$ & $1.83(1.06-2.89)$ & $1.83(1.05-3.17)$ & $1.84(1.06-3.21)$ & $1.85(1.06-3.22)$ \\
\hline$p$ for trend & 0.018 & 0.024 & 0.023 & 0.024 & 0.023 \\
\hline
\end{tabular}

*Analysis = Cox's Proportional Hazard Models. Model 1 = adjusted for age, number of teeth, smoking status, and tooth brushing frequency. Model $2=$ Model $1+$ adjustment for baseline BMI, cholesterol, history of atherosclerotic cardiovascular disease, history of hypertension. Model $3=$ Model $2+$ adjustment for education years, dental attendance, marital status, and socioeconomic status.

$\mathrm{HR}=$ hazard ratio; $\mathrm{CI}=$ confidence interval; values in bold signify statistical significance $\mathrm{p}<0.05$.

This article is protected by copyright. All rights reserved. 

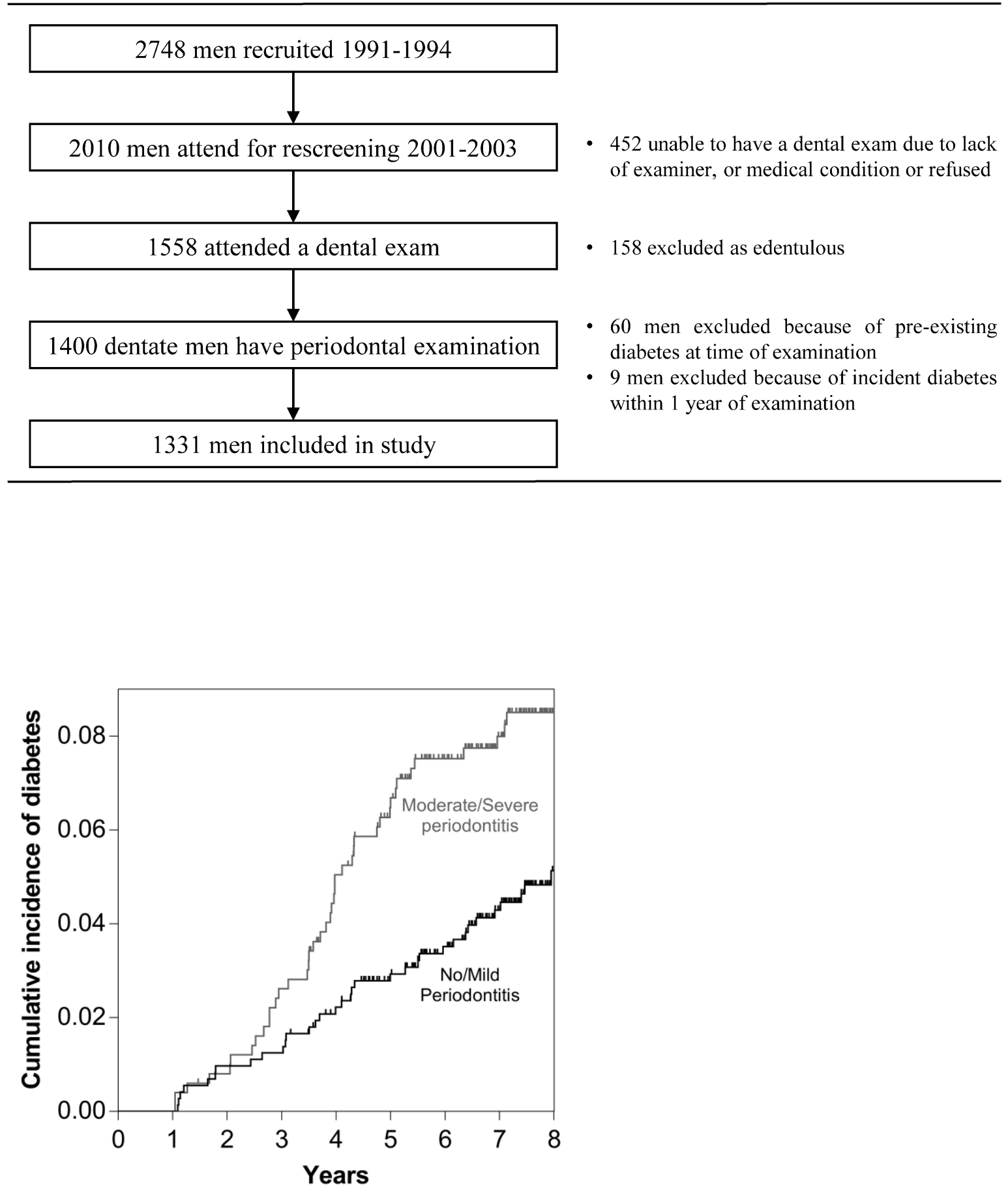

This article is protected by copyright. All rights reserved. 